Research Article

\title{
Up-regulation of RIP1 and IPS-1 in chronic HBV infected patients
}

\author{
Minoo Safari-Arababadi ${ }^{1}$ (D), Mohammad Hossein Modarressi ${ }^{1,2}$ (iD) and Mohammad Kazemi Arababadi ${ }^{3,4}$ iD \\ ${ }^{1}$ Department of Genetics, Faculty of Basic Sciences, Science and Research Branch, Islamic Azad University, \\ Tehran, Iran. \\ ${ }^{2}$ Department of Medical Genetics, School of Medicine, Tehran University of Medical Sciences, Tehran, Iran. \\ ${ }^{3}$ Immunology of Infectious Diseases Research Center, Research Institute of Basic Medical Sciences, \\ Rafsanjan University of Medical Sciences, Rafsanjan, Iran. \\ ${ }^{4}$ Department of Laboratory Sciences, Faculty of Paramedicine, Rafsanjan University of Medical Sciences, \\ Rafsanjan, Iran.
}

\begin{abstract}
IPS-1 and RIP1 are the main downstream molecules of RIG1 and MDA5, as intracytoplasmic receptors, which are the main receptors involved in recognition of internal and external viral double-stranded RNA. In this project, mRNA levels of IPS-1 and RIP1 were investigated in the peripheral blood immune cells of chronic hepatitis B (CHB) patients. IPS-1 and RIP1 mRNA levels were measured in $60 \mathrm{CHB}$ patients and 120 healthy subjects, using RT-qPCR technique. A significant increase in expression levels of IPS-1 and RIP1 was found in patients when compared to healthy individuals. There was no correlation between IPS-1 and RIP1expression levels with the serum levels of hepatitis B e-Antigen ( $\mathrm{HBeAg}$ ) and liver enzymes in patients. Based on the results, it seems that IPS-1 and RIP1 can participate in the induction of low chronic inflammation, which is a main cause of liver cirrhosis and hepatocellular carcinoma.
\end{abstract}

Keywords: Innate immunity, hepatitis B, RIP1, IPS-1.

Received: March 14, 2018; Accepted: August 02, 2018.

\section{Introduction}

Chronic HBV-infected (CHB) patient ssuffer from mild symptoms of liver inflammation, which is a main cause of liver cirrhosis and hepatocellular carcinoma (HCC) (Chan and Jia, 2011). Accordingly, several investigations reported that the cause of cirrhosis and HCC could be $\mathrm{CHB}$ and the low levels of chronic immune responses to HBV (Mendy et al., 2010).

The pattern recognition receptors (PRRs) identify internal, damage-associated molecular patterns (DAMPs), and external, pathogen-associated molecular patterns (PAMPs), proteins motifs (Abreu and Arditi, 2004; Sepehri et al., 2016a). PRRs recognize DAMPs and PAMPs and accordingly induce expression of some pro-inflammatory molecules that either participate in the induction of appropriate immune responses against pathogens or induce proinflammatory-based complications such as liver cirrhosis and HCC (Zhang et al., 2012; Bagheri et al., 2014; KarimiGoogheri and Arababadi, 2014; Momeni et al., 2014; Moreau, 2016; Sepehri et al., 2016b; Sun et al., 2016; Sepehri

Send correspondence to Mohammad Kazemi Arababadi, Immunology of Infectious Diseases Research Center, Research Institute of Basic Medical Sciences, Rafsanjan University of Medical Sciences, 7716643861 Rafsanjan, Iran. E-mail: dr.kazemi@ rums.ac.ir et al., 2017). One of the PAMPs that is recognized by the immune system is viral dsRNA, which is produced by both DNA and RNA genomic viruses (Gerelsaikhan et al., 1996; Harrison et al., 2001; Park, 2004; Hu and Liu, 2017). Retinoic acid-inducible gene 1 (RIG-1) and melanoma differentiation-associated protein 5 (MDA5) are the most important PRRs that recognize viral dsRNA (Gerelsaikhan et al., 1996; Harrison et al., 2001; Hu and Liu, 2017) as microbial PAMPs (Hagele et al., 2009; Ghosh et al., 2013). MDA5 and RIG-1 have a card caspase domain (Jiang et al., 2011; Triantafilou and Triantafilou, 2012) that activate signaling pathways of adaptor proteins after dsRNA recognition. IFN- $\beta$ promoter stimulator-1 (IPS-1) and receptor interacting protein 1 (RIP1) are adapter molecules that activate both MDA5 and RIG-1 signaling pathways. MDA5 and RIG-1 signaling pathways are responsible for production of inflammatory cytokines, using activation of proinflammatory transcription factors, and consequently inhibiting virus replication (Guo et al., 2009).

Accordingly, the IPS-1 and RIP-1 molecules trigger the activation of some transcription factors such as interferon regulatory factor 3 (IRF3) and IRF7, resulting in the transcription of IFN-1 and other inflammatory cytokines genes that play key roles in induction of inflammation 
(Szabo et al., 2012). Additionally, low expression of proinflammatory molecules during CHB is the mechanism responsible for deterioration of $\mathrm{CHB}$ complications such as liver cirrhosis and HCC (Chan and Jia, 2011; Kim et al., 2017; Yoo et al., 2017).

Therefore, alterations in the expression of these molecules may be associated with low chronic inflammation in CHB patients. Our previous investigations revealed that mRNA levels of MDA5 and RIG-1 are decreased and increased, respectively, in CHB patients (Ebrahim et al., 2015). Due to the important roles of IPS- 1 and RIP1 in the intracellular signaling pathways of MDA5 and RIG-1, the alteration in MDA5 and RIG-1 may be associated with altered expression of IPS-1 and RIP1. Therefore, this project aimed to investigate RIP1 and IPS-1 mRNA levels in Iranian CHB patients. The relationship between the expression of IPS-1 and RIPI and serum level of liver functions markers, and hepatitis B e-Antigen ( $\mathrm{HBeAg}$ ) were determined in this project.

\section{Subjects and Methods}

\section{Subjects}

In this cross-sectional study, 120 healthy controls and 60 CHB patients (28 males and 32 females with age of 20-60 years old) were enrolled and referred to Razie Firroz Hospital, Kerman, Iran. The healthy controls and CHB patients were evaluated regarding IPS-1 and RIP1 expression levels and serum levels of HBeAg, HBV-DNA, and liver functional markers including aspartate aminotransferase (AST), alkaline phosphatase (ALP), alanine aminotransferase (ALT), direct bilirubin (DB), and total bilirubin (TB). Blood samples were collected from participants in $5.5-\mathrm{mL}$ tubes with anticoagulant coating (to examine expression of IPS-1 and RIP1) or without anticoagulant coating (to examine $\mathrm{HBeAg}$, HBV-DNA, and serum levels of liver functional markers). Based on the "Guide of Prevention and Treatment in Viral Hepatitis" (Chinese Society of Infectious Diseases and Parasitology, 2008), an internal medicine specialist diagnosed CHB based on the hepatitis B surface antigen (HBsAg) positivity for more than six months and clinical presentations. Healthy controls were matched for age and sex. Exclusion and inclusion criteria described in our previous investigations were performed on these patients (Askari et al., 2016). The Ethical Committee of the Rafsanjan University of Medical Sciences certified the protocol of this study (Code: IR.RUMS.REC.1394.188), and before sample collection, a written informed consent was obtained from participants.

\section{Measurement of serological HBV markers}

ELISA (enzyme-linked-immunosorbent-assay) kits (Behring, Marburg, Germany) were used for determination of HBsAg and HBeAg according to the manufacturer's protocol.

\section{HBV-DNA extraction and qPCR assay}

HBV-DNA was extracted and quantified, respectively, with commercial kits from Cinnaclon (Tehran, Iran) and Design Primer (London, UK).

\section{RNA extraction, cDNA synthesis, reverse} transcription, and RT-qPCR

At first, for checking the expression levels of IPS-1 and RIP1, total mRNA was extracted by using a commercial kit from Cinnaclon (Tehran, Iran). The quantity and quality of extracted mRNA were evaluated by spectrophotometer UV at 260-280 nm and agarose gel electrophoresis, respectively. cDNA synthesis (Parstoos Company, Tehran, Iran) and RT-qPCR (Genet Bio Company, South Korea) conditions and protocols were described completely in our previous study (Ebrahim et al., 2015), except for the primer sequences which were designed using Primer3 software and are presented in Table 1. A $\beta$-actin gene was used as endogenous control for the normalization of expression levels. Changes in the expression levels of IPS-1 and RIPI were reported as fold-changes (Ebrahim et al., 2015).

\section{Liver function tests (LFT)}

For examination of the serum levels of AST, ALP, ALT, DB, and TB, Pars Azmoon commercial kits (Tehran, Iran) were used.

\section{Data analysis and statistical methods}

The raw data for the RIP1 and IPS-1 mRNA levels were not in accordance with normal patterns, hence, the non-parametric test Mann-Whitney U test, implemented in SPSS software version 18, was used to compare CHB patients and healthy controls regarding the mRNA levels of IPS-1 and RIP1. Accordingly, Spearman's test, as a nonparametric test, was used to evaluate the correlation between RIP1 and IPS-1 and serum levels of liver enzymes in the CHB patients. All samples were included in the statistical analysis and the significance level in the tests was set at $p<0.05$. The mRNA levels were presented using the $2^{-\Delta \Delta c t}$ formula, as described in our previous investigation (Ayoobi et al., 2013).

Table 1 - Primer sequences used in real-time PCR.

\begin{tabular}{llc}
\hline Gene & & Primers \\
\hline IPS-1 & Forward & AGCAAGAGACCAGGATCGAC \\
& Reverse & GGGTATTGAAGAGATGCCAGAG \\
RIP1 & Forward & AGAAAGTGTAGAAGAGGACGTG \\
& Reverse & AGGTACTGCCACACAATCAAG \\
$\beta$-actin & Forward & GCATGGGTCAGAAGGATTC \\
& Reverse & GTCCCAGTTGGTGACGAT \\
\hline
\end{tabular}




\section{Results}

Serum levels of liver enzymes and direct/total bilirubin in CHB patients

Serum levels of ALT, ALP, AST, DB, and TB were evaluated in these patients in our previous investigation, so the data was presented in a previous article (Askari et al., 2016).

\section{HBV serum markers}

All patients were positive for $\mathrm{HBsAg}$, while $\mathrm{HBeAg}$ was positive in only $4(6.66 \%)$ CHB patients.

Because viral load has significant effects on the expression of immune-related molecules (Michalak et al., 2000), HBV-DNA viral load was evaluated in this study.

IPS-1 and RIP1 mRNA levels in patients and controls

The IPS-1 mRNA level in CHB patients was 1.9279 (range $0.1429-11.2525$ ) and in healthy subjects it was $0.0672(0.0185-0.1438)$ (Figure 1). The difference between the two groups was statistically significant $(p<0.001)$.

RIP1 mRNA levels in CHB patients were significantly $(p<0.001)$ increased $(16.7373$; range $(0.8017$ $677.2051)$ in comparison to healthy subjects (2.7406; range 0.2499-9.1961). Figure 1 illustrates IPS-1 and RIP1 mRNA levels in CHB and healthy controls.

\section{Expression of IPS-1 and RIP1 genes in male and female patients}

Mann-Whitney's test showed that there were no significant differences in the expression of RIP1 $(p=0.272)$ and IPS- $1(p=0.665)$ in both male ( 28 cases) and female (32 cases) patients (Figure 2 ).

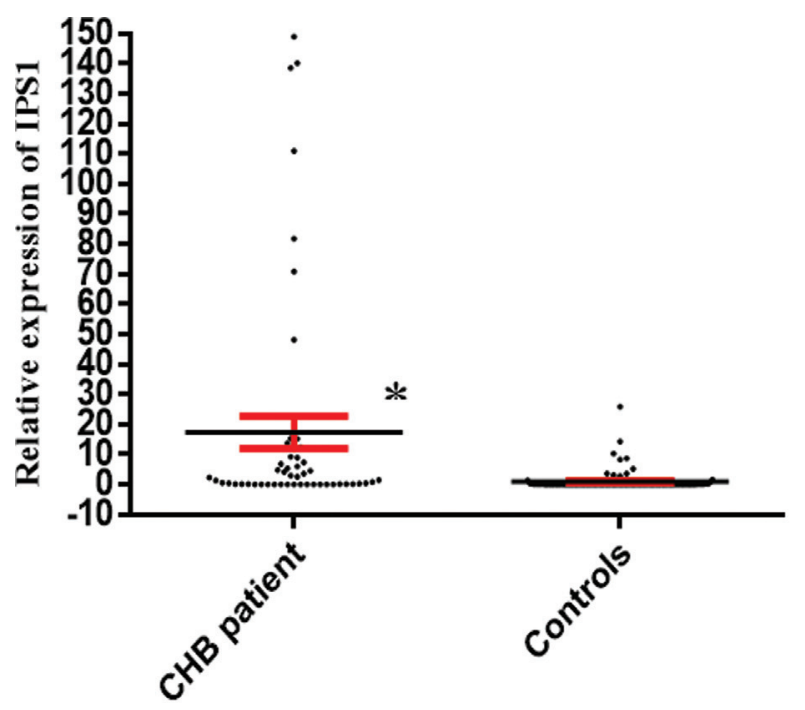

IPS-1 and RIP1 mRNA levels in the HBeAg-positive and negative $\mathrm{CHB}$ patients

The median expression of IPS- 1 and RIPI in $\mathrm{HBeAg}$ positive CHB patients was 22.00 and 15.75 , respectively, while these values in $\mathrm{HBeAg}$-negative patients were 26.88 and 27.47. Statistical analysis showed that the differences were not significant for the expression of IPS-1 $(p=0.562)$ and RIP1 ( $p=0.369$ ) (Figure 3).

\section{Relationship between IPS-1 and RIP1 gene expressions with liver functional markers in $\mathrm{CHB}$ patients}

Spearman's test was used to determine the correlation between IPS-1 and RIPI gene expression with serum levels of liver enzymes. Based on the data presented in Table 2, there was no significant correlation between expression of the two genes and the liver functional markers.

\section{Discussion}

The results showed that mRNA levels of IPS- 1 and RIP1 significantly increased in the CHB patients. Because CHB patients suffered from chronic inflammation, and this is a reason for induction of liver cirrhosis and hepatocellular carcinoma (HCC), the most important CHB complications, it may be hypothesized that the up-regulation of IPS- 1 and RIP 1 expression is a crucial mechanism to induce or stimulate chronic inflammation, and consequently liver cirrhosis and HCC. Interestingly, our previous investigation on the same CHB patients revealed that the mRNA levels of RIG-1, the upstream molecule of IPS-1 and RIP1, was significantly increased, while MDA5 mRNA levels were decreased (Ebrahim et al., 2015). Because RIG-1 and MDA5 are the innate immune receptors that recognize mi-

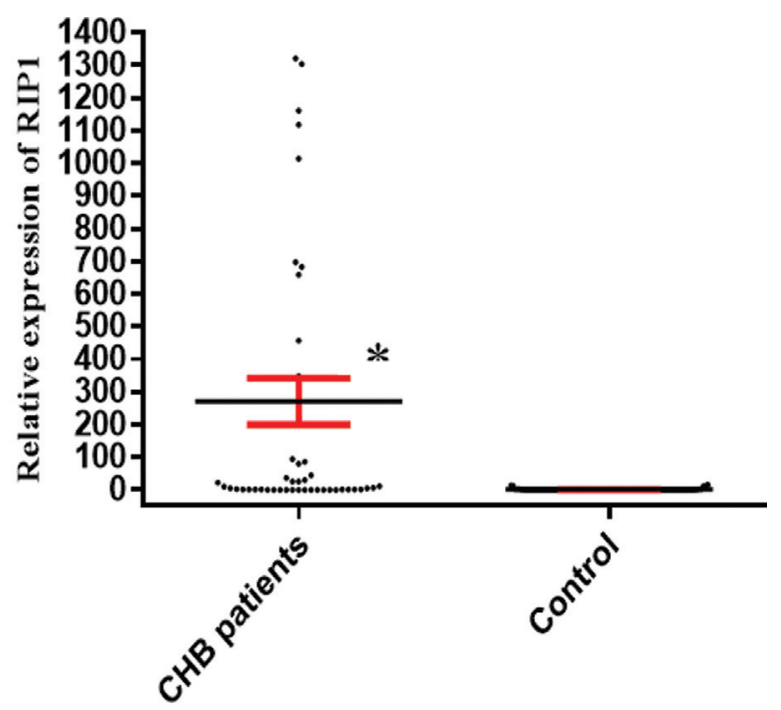

Figure 1 - IPS-1 and RIP1 gene expression in patients with chronic hepatitis B and controls. IPS-1 and RIP1 mRNA levels were significantly increased in patients when compared to healthy controls. Data are presented as mean \pm standard errors. The results regarding the expression levels of IPS-1 and RIP1 are reported as fold-changes (Ebrahim et al., 2015). *p-value $<0.001$ 

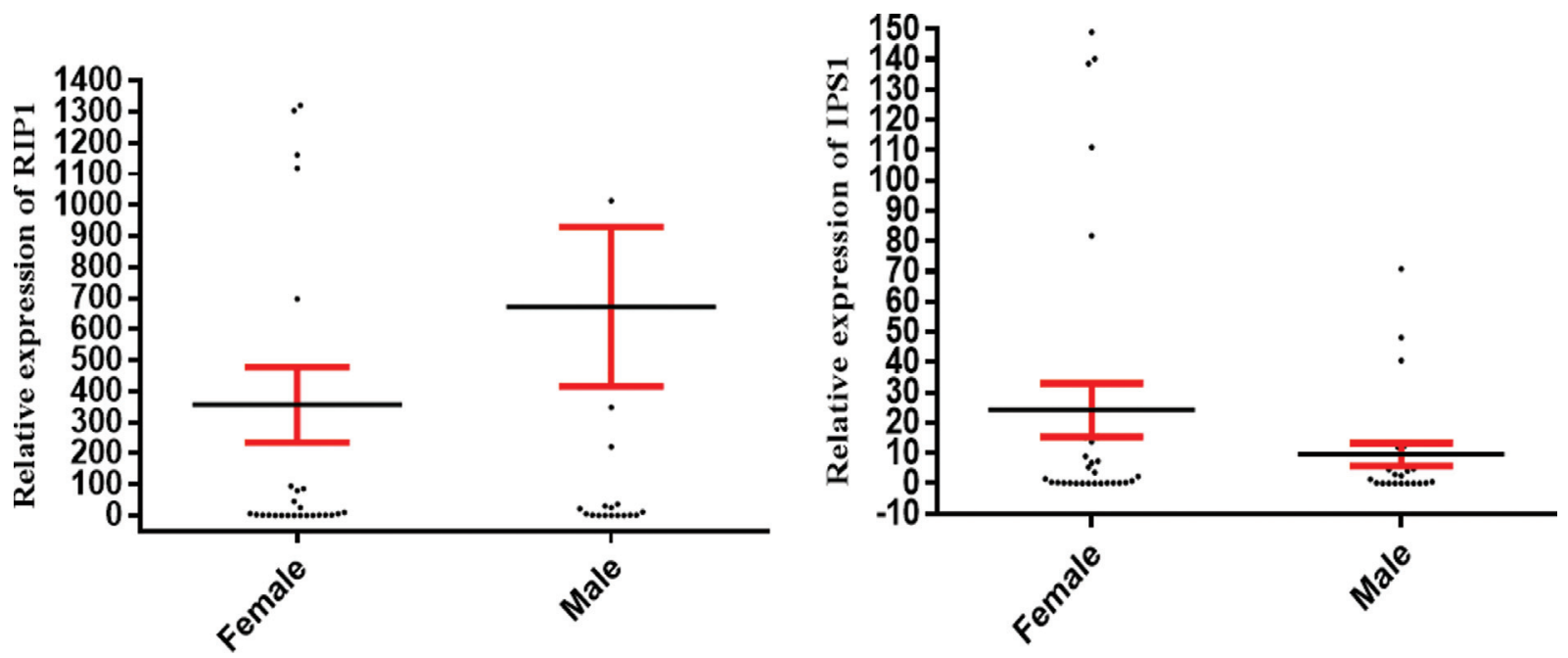

Figure 2 - RIPI and IPS-1 gene expression in male and female patients with chronic hepatitis B. The figure shows that mRNA levels of IPS-1 and RIP1 did not differ between male and female patients with chronic hepatitis B. Data are presented as mean \pm standard errors. The results regarding the expression levels of IPS-1 and RIP1 are reported as fold-changes (Ebrahim et al., 2015).
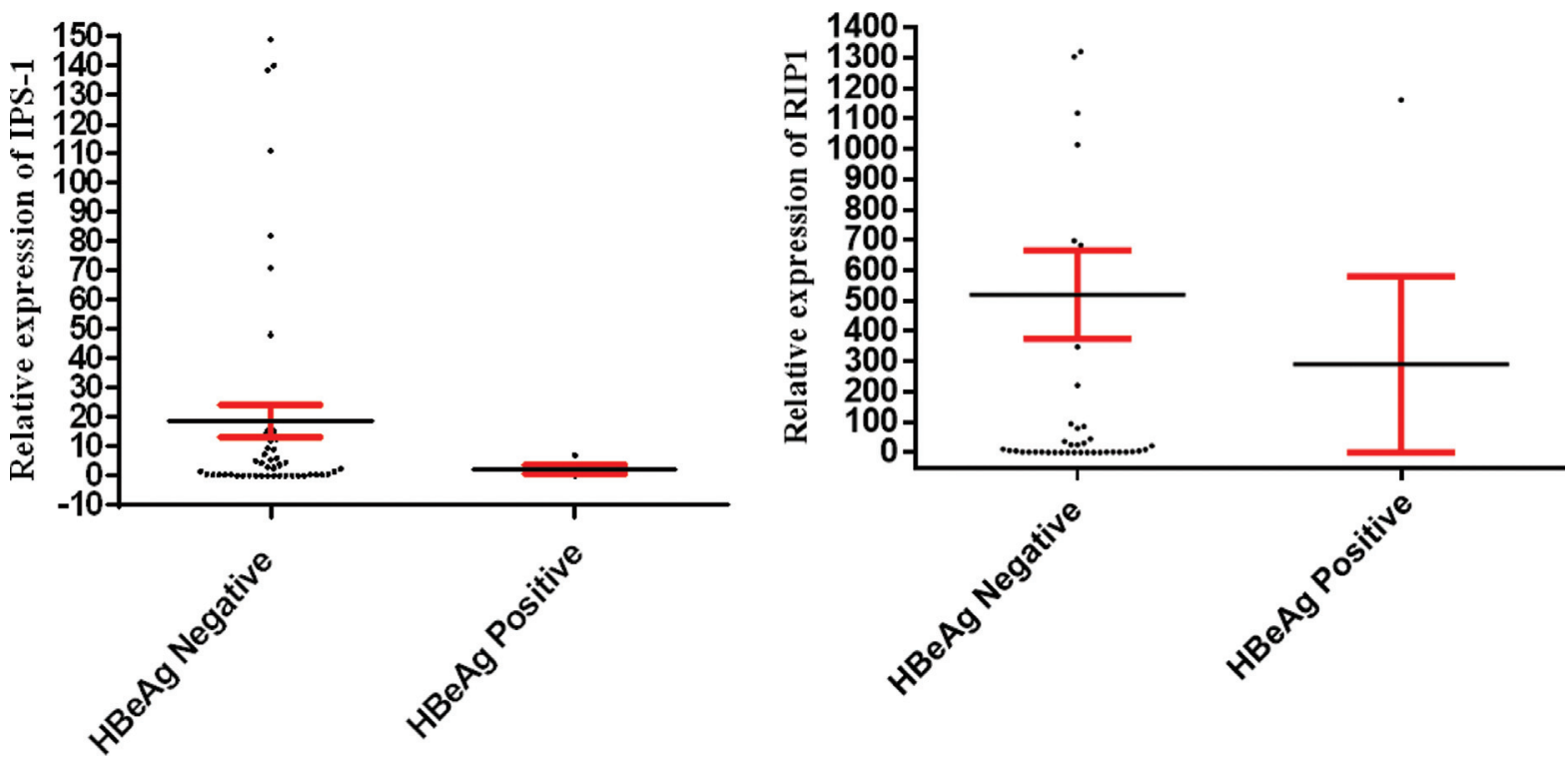

Figure 3 - IPS- 1 and RIP1 gene expression in HbeAg-positive and negative patients with chronic hepatitis B. The figure shows that HBeAg positive and negative patients did not show differences in their IPS-1 and RIP1 mRNA levels. Data are presented as mean \pm standard errors. The results regarding the expression levels of IPS-1 and RIPI are reported as fold-changes (Ebrahim et al., 2015).

Table 2 - Associations of IPS-1 and RIP1 genes with serum levels of liver enzymes.

\begin{tabular}{|c|c|c|c|c|c|c|c|c|c|c|}
\hline & & & $\begin{array}{c}\text { Viral copy } \\
\text { number }\end{array}$ & IPS1 & RIP1 & DB & TB & ALT & ALK & AST \\
\hline \multirow{6}{*}{$\begin{array}{l}\text { Spearman's } \\
\text { rho }\end{array}$} & Viral copy & Correlation coefficient & 1.000 & 0.142 & 0.197 & 0.208 & 0.163 & 0.093 & 0.126 & 0.132 \\
\hline & number & $p$-value & - & 0.348 & 0.190 & 0.139 & 0.249 & 0.513 & 0.375 & 0.351 \\
\hline & IPS-1 & Correlation coefficient & 0.142 & 1.000 & $0.757^{*}$ & 0.094 & -0.071 & 0.125 & 0.099 & $0.275^{* *}$ \\
\hline & & $p$-value & 0.348 & - & 0.000 & 0.507 & 0.616 & 0.377 & 0.485 & 0.049 \\
\hline & RIP1 & Correlation coefficient & 0.197 & $0.757^{*}$ & 1.000 & 0.256 & 0.113 & 0.087 & 0.173 & 0.212 \\
\hline & & $p$-value & 0.190 & 0.000 & - & 0.067 & 0.423 & 0.542 & 0.221 & 0.131 \\
\hline
\end{tabular}

Spearman's test revealed that there were significant, yet poor positive correlations between IPS-1 and RIP1 $(*)$ and between IPS-1 and AST (**), respectively. 
crobial PAMPs and then activate downstream molecules, including IPS-1 and RIP1, which consequently result in activation of pro-inflammatory transcription factors such as IRF3 and IRF7 (Reikine et al., 2014; Li et al., 2018), it seems that RIG-1/MDA5 and its downstream molecules can be considered as unknown parts of the CHB-related liver cirrhosis and HCC puzzle. Interestingly, there is evidence in favor of this hypothesis. For example, Zhao et al. (2012) used monocyte-derived dendritic cells (moDCs) that had been derived from CHB patients to evaluate expression of RIG-1 and IPS-1. They reported that, although expression of $R I G-1$ decreased in the moDCs, stimulation of the cells with vesicular stomatitis virus (VSV) in in vitro condition led to an up-regulation of both RIG-1 and IPS-1 after 8 and 16 hours, respectively. However, the expression of $R I G-1$ was decreased after stimulation of the cells for 16 hours. As IPS- 1 levels were higher at 16 hours after stimulation and did not decrease, it may be hypothesized that IPS-1 is induced by other unknown pathways. Moreover, it also can be concluded that IPS-1 participates in the induction of inflammation more than RIG-1, which needs to be explored by additional studies. Ye et al. (2012) also showed that RIP1 plays an important role in the induction of cirrhosis: RIP1 releases cytochrome $\mathrm{C}$ from mitochondria and, through TNF- $\alpha$, causes ROS and mitochondrial dysfunction, resulting in necrosis, which is seen in the liver of the patients who suffer from liver cirrhosis. While the results revealed a certain but rather minor relationship between IPS-1 and AST, there was no a significant relation ship between mRNA levels of IPS- 1 and RIP1 and liver function markers (Table 2). Nonetheless, a positive relationship between ALT and RIG- 1/IPS-1 has been reported (Zhao et al., 2012).

As all of the patients who participated in the current investigation had normal ranges of liver function markers, there was no relationship between IPS-1 and RIP1 mRNA levels and serum levels of liver function markers were not significant. However, previous investigations revealed that AST is a critical marker of liver inflammation, which may be associated with liver cirrhosis and HCC (Wang et al., 2018). Due to the positive correlation between AST and IPS-1, it may be hypothesized that IPS-1 is an inducer of liver inflammation. Accordingly, following the patients in a cohort investigation could be useful to clarify the roles played by IPS-1 and RIP1 and their up/down-stream molecules in the pathogenesis of chronic hepatitis.

$\mathrm{HBeAg}$ was not associated with the expression of IPS-1 and RIP1. Our previous investigations on RIG-1 and MDA5 had similar results and revealed that there was no relationship between the expression of $\mathrm{HBeAg}$ by $\mathrm{HBV}$ and expression of MDA5 and RIG-1 by host immune cells (Ebrahim et al., 2015). Interestingly, our previous investigations on other innate immunity molecules showed that there was no association between the expression of innate immunity-related molecules such as toll-like receptor 9
(TLR9) and its downstream molecules with the expression of HBeAg (Momeni et al., 2014; Askari et al., 2016). Thus, it may be hypothesized that HBeAg does not alter the expression of innate immunity-related molecules in Iranian CHB patients.

Additionally, there was no significant relationship between mRNA levels of IPS-1/RIP1 and gender for the CHB patients. Our previous investigations also had the same results and revealed that mRNA levels of MDA5, RIG-1, TLR9, myeloid differentiation primary response gene 88 (MYD88), TIR-domain-containing adapter-inducing interferon- $\beta$ (TRIF), Interleukin-1 receptor-associated kinase 1 (IRAK1), IRAK4, tumor necrosis factor receptor-associated factor 3 (TRAF3), TRAF6, nuclear factor B (NF-kB), and interferon regulatory factor 7 (IRF7) were not associated with the participant's gender (Ayoobi et al., 2013; Sajadi et al., 2013; Momeni et al., 2014). Although several investigations proved that gender is a factor that can alter the expression of immune-related molecules (OerteltPrigione, 2012; Klein and Flanagan, 2016; Ruggieri et al., 2016), our investigations were unable to show such differences in male and female CHB patients. The result may be related to the infectivity to HBV, different genetic status, and environmental factors that need to be explored by further investigations. Thus, it seems that gender is not associated with the expression of innate immunity molecules in Iranian CHB patients. Additionally, because high variation for immune-related molecules is common (Ayoobi et al., 2013; Sajadi et al., 2013; Momeni et al., 2014), increasing the sample size may reveal significant differences between groups (based on gender and $\mathrm{HBeAg}$ positivity) for these molecules of interest.

\section{Acknowledgments}

The scholarship of this project was sponsored by Rafsanjan University of Medical Sciences.

\section{Conflict of Interest}

The authors have no conflict of interest regarding the results reported in the article with any commercial or other association.

\section{Author contributions}

MS-A conducted the experiments, including both absolute and relative Real-Time PCR and RNA extraction, cDNA synthesize and DNA extractions. MHM conceived and designed the study and wrote a manuscript draft, MKA conceived and designed the study, wrote the manuscript draft, analyzed the data and submitted the manuscript and revise it, all authors read and approved the final version. 


\section{References}

Abreu MT and Arditi M (2004) Innate immunity and toll-like receptors: clinical implications of basic science research. J Pediatr 144:421-429.

Askari A, Nosratabadi R, Khaleghinia M, Zainodini N, Kennedy D, Shabani Z and Kazemi Arababadi M (2016) Evaluation of NLRC4, NLRP1, and NLRP3, as components of inflammasomes, in chronic hepatitis B virus-infected patients. Viral Immunol 29:496-501.

Ayoobi F, Hassanshahi G, Zainodini N, Khorramdelazad H, Arababadi MK and Kennedy D (2013) Reduced expression of TRIF in chronic HBV infected Iranian patients. Clin Res Hepatol Gastroenterol 37:491-495.

Bagheri V, Askari A, Arababadi MK and Kennedy D (2014) Can Toll-Like Receptor (TLR) 2 be considered as a new target for immunotherapy against hepatitis B infection? Hum Immunol 75:549-554.

Chan HL and Jia J (2011) Chronic hepatitis B in Asia - new insights from the past decade. J Gastroenterol Hepatol 26(Suppl 1):131-137.

Chinese Society of Infectious Diseases and Parasitology (2008) The guide of prevention and treatment in viral hepatitis. Chin J Hepatol: 324-329.

Ebrahim M, Mirzaei V, Bidaki R, Shabani Z, Daneshvar H, Karimi-Googheri M, Khaleghinia M, Afrooz MR, Yousefpoor Y and Arababadi MK (2015) Are RIG-1 and MDA5 expressions associated with chronic HBV infection? Viral Immunol 28:504-508.

Gerelsaikhan T, Tavis JE and Bruss V (1996) Hepatitis B virus nucleocapsid envelopment does not occur without genomic DNA synthesis. J Virology 70:4269-4274.

Ghosh M, Shen Z, Fahey JV, Crist SG, Patel M, Smith JM and Wira CR (2013) Pathogen recognition in the human female reproductive tract: expression of intracellular cytosolic sensors NOD1, NOD2, RIG-1, and MDA5 and response to HIV-1 and Neisseria gonorrhea. Am J Reprod Immunol 69:41-51.

Guo H, Jiang D, Ma D, Chang J, Dougherty AM, Cuconati A, Block TM and Guo JT (2009) Activation of pattern recognition receptor-mediated innate immunity inhibits the replication of hepatitis B virus in human hepatocyte-derived cells. J Virol 83:847-858.

Hagele H, Allam R, Pawar RD and Anders HJ (2009) Double-stranded RNA activates type I interferon secretion in glomerular endothelial cells via retinoic acid-inducible gene (RIG)-1. Nephrol Dial Transplant 24:3312-3318.

Harrison GL, Murray-McIntosh R and Penny D (2001) Hepatitis B virus genotypes: A South Pacific perspective. Pacific Health Dialog 8:188-192.

$\mathrm{Hu} \mathrm{J}$ and Liu K (2017) Complete and incomplete hepatitis B virus particles: Formation, function, and application. Viruses 9:E56.

Jiang F, Ramanathan A, Miller MT, Tang GQ, Gale M Jr, Patel SS and Marcotrigiano J (2011) Structural basis of RNA recognition and activation by innate immune receptor RIG-I. Nature 479:423-427.

Karimi-Googheri M and Arababadi MK (2014) TLR3 plays significant roles against hepatitis B virus. Mol Biol Rep 41:3279-3286.

Kim SY, Kyaw YY and Cheong J (2017) Functional interaction of endoplasmic reticulum stress and hepatitis B virus in the pathogenesis of liver diseases. World J Gastroenterol 23:7657-7665.

Klein SL and Flanagan KL (2016) Sex differences in immune responses. Nat Rev Immunol 16:626-638.

Li L, Yang R, Feng M, Guo Y, Wang Y, Guo J and Lu X (2018) Rig-I is involved in inflammation through the IPS1/TRAF(6) pathway in astrocytes under chemical hypoxia. Neurosci Lett 672:46-52.

Mendy ME, Welzel T, Lesi OA, Hainaut P, Hall AJ, Kuniholm $\mathrm{MH}$, McConkey S, Goedert JJ, Kaye S, Rowland-Jones S et al. (2010) Hepatitis B viral load and risk for liver cirrhosis and hepatocellular carcinoma in Gambia, West Africa. J Viral Hepat 17:115-122.

Michalak TI, Hodgson PD and Churchill ND (2000) Posttranscriptional inhibition of class I major histocompatibility complex presentation on hepatocytes and lymphoid cells in chronic woodchuck hepatitis virus infection. J Virology 74:4483-4494.

Momeni M, Zainodini N, Bidaki R, Hassanshahi G, Daneshvar H, Khaleghinia M, Ebrahim M, Karimi-Googheri M, Askari A, Arababadi MK et al. (2014) Decreased expression of toll like receptor signaling molecules in chronic HBV infected patients. Hum Immunol 75:15-19.

Moreau R (2016) The pathogenesis of ACLF: The inflammatory response and immune function. Semin Liver Dis 36:133140.

Oertelt-Prigione S (2012) The influence of sex and gender on the immune response. Autoimmun Rev 11:A479-485.

Park JH (2004) Hepatitis B virus surface antigen: A multifaceted protein. Korean J Hepatol 10:248-259.

Reikine S, Nguyen JB and Modis Y (2014) Pattern recognition and signaling mechanisms of RIG-I and MDA5. Front Immunol 5:342.

Ruggieri A, Anticoli S, D'Ambrosio A, Giordani L and Viora M (2016) The influence of sex and gender on immunity, infection and vaccination. Annali Ist Sup Sanita 52:198-204.

Sajadi SM, Mirzaei V, Hassanshahi G, Khorramdelazad H, Daredor HY, Hosseini SM, Moogooi M, Ravary A, Arababadi MK and Kennedy D (2013) Decreased expressions of Tolllike receptor 9 and its signaling molecules in chronic hepatitis B virus-infected patients. Arch Pathol Lab Med 137:1674-1679.

Sepehri Z, Kiani Z, Nasiri AA and Kohan F (2016a) Toll-like receptor 2 and type 2 diabetes. Cell Mol Biol Lett 21:2.

Sepehri Z, Kiani Z, Alavian SM, Arababadi MK and Kennedy D (2016b) The link between TLR7 signaling and hepatitis B virus infection. Life Sci 158:63-69.

Sepehri Z, Kiani Z, Kohan F, Alavian SM and Ghavami S (2017) Toll like receptor 4 and hepatocellular carcinoma; A systematic review. Life Sci 179:80-87.

Sun L, Dai J, Hu W and Wang J (2016) Expression of toll-like receptors in hepatic cirrhosis and hepatocellular carcinoma. Genet Mol Res 15:gmr7419.

Szabo A, Bene K, Gogolak P, Rethi B, Lanyi A, Jankovich I, Dezso B and Rajnavolgyi E (2012) RLR-mediated production of interferon-beta by a human dendritic cell subset and its role in virus-specific immunity. J Leukoc Biol 92:159169.

Triantafilou $K$ and Triantafilou M (2012) Visualising PAMP-PRR interactions using nanoscale imaging. Methods Mol Biol 799:253-266. 
Wang J, Xia J, Zhang R, Yan X, Yang Y, Zhao XA, Chang H, Wang G, Chen G, Liu Y et al. (2018) A novel index using routinely clinical parameters for predicting significant liver inflammation in chronic hepatitis B. J Viral Hepat 9:12925.

Ye Y-C, Wang H-J, Yu L, Tashiro S-I, Onodera S and Ikejima T (2012) RIP1-mediated mitochondrial dysfunction and ROS production contributed to tumor necrosis factor alpha-induced L929 cell necroptosis and autophagy. Int Immunopharmacol 14:674-682.

Yoo S, Wang W, Wang Q, Fiel MI, Lee E, Hiotis SP and Zhu J (2017) A pilot systematic genomic comparison of recurrence risks of hepatitis B virus-associated hepatocellular carcinoma with low- and high-degree liver fibrosis. BMC Medicine 15:214.
Zhang H-L, Yu L-X, Yang W, Tang L, Lin Y, Wu H, Zhai B, Tan Y-X, Shan L and Liu Q (2012) Profound impact of gut homeostasis on chemically-induced pro-tumorigenic inflammation and hepatocarcinogenesis in rats. J Hepatol 57:803812.

Zhao G, An B, Zhou H, Wang H, Xu Y, Xiang X, Dong Z, An F, $\mathrm{Yu} \mathrm{D}$ and Wang W (2012) Impairment of the retinoic acidinducible gene-I-IFN- $\beta$ signaling pathway in chronic hepatitis B virus infection. Int J Mol Med 30:1498-1504.

Associate Editor: Ricardo G. Correa

License information: This is an open-access article distributed under the terms of the Creative Commons Attribution License (type CC-BY), which permits unrestricted use, distribution and reproduction in any medium, provided the original article is properly cited. 